\title{
Saúde e antropologia:
}

\author{
contribuições à interpretação da condição humana em ciências da saúde *
}

Tullio Seppilli ${ }^{1}$

\section{Introdução}

A fundação teórico-empírica da antropologia parece marcada por uma questão crucial que atravessa sua história e as ciências humanas como um todo, com heterogêneas e relevantes consequências em seus horizontes de referência, linhas de fundo, metodologias investigativas, modelos interpretativos, diretrizes próprias de pesquisa, além dos efeitos e uso social de seus resultados. Esta questão, como foi sendo "resolvida", pesou fortemente sobre fenômenos humanos de grande expressão social, legitimando ou contrastando, por exemplo, racismo, colonialismo ou "exclusão" feminina, incidindo sobre atitudes ante o desvio ou a diversidade, influenciando o próprio paradigma de nossa medicina oficial. Especialmente neste terreno, as ciências humanas implicam diretamente algumas das mais relevantes expressões das dinâmicas de hegemonia e de poder, tornando-se provavelmente as "menos neutras" no panorama de contribuição das ciências à medicina ou saúde.

Questão crucial das ciências humanas, seu núcleo duro (um debate ainda vivo), sintética e inapropriadamente definida como a questão do relacionamento entre natureza e história. Tentarei, aqui, uma formulação mais atual, deixando em aberto questões ineludíveis para efetivas interpretações da condição humana, tendo em vista contribuir com a ciência na saúde.

Quanto e como pesa, no comportamento dos indivíduos, a sua natureza biológica? Quanto e como pesam as suas experiências e o seu viver em um determinado contexto histórico-social? Quanto e como a disposição, o funcionamento e o devir histórico de uma sociedade dependem da sua própria lógica global, mesmo além da natureza biológica dos próprios indivíduos que a compõem, das "necessidades naturais" desses indivíduos e de seu estágio evolutivo no processo de hominização?

Se aquilo que diversifica as várias civilizações deriva da heterogeneidade dos seus percursos históricos e dos contextos ambientais com os quais tais percursos tiveram que confrontar-se, não de uma diferente constituição biológica dos indivíduos que a compõem, aquilo que "permanece similar" em toda civilização que com frequência chamamos de "universalmente humano" - depende somente da substancial homogeneidade biológica do homo sapiens? Somente daquilo que a humanidade alcançou como estágio atual no seu processo evolutivo? Não

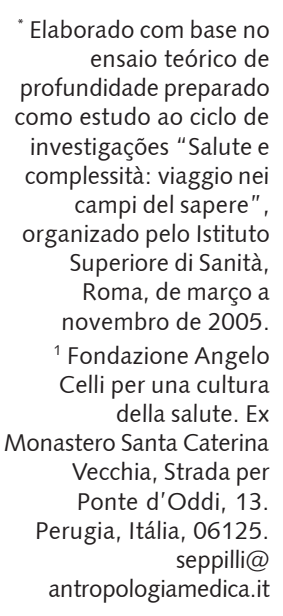


dependeria também de características que ultrapassam a esfera biológica e são, mesmo assim, comuns a todo tipo de existência humana enraizada em uma rede de relações sociais? Também de algumas matrizes não biológicas e, mesmo assim, inerentes a qualquer condição social, independentemente do tipo de civilização? Qual grau de autonomia é possível supor, em síntese, e quais interações entre o "nível" de organização da constituição biológica individual e aquele do sistema social? Em que medida e por meio de quais processos o horizonte social se integra, sem unicamente sobrepor-se, com a natureza biológica dos próprios indivíduos no processo de formação de pessoas concretas, sua subjetividade e seus comportamentos?

O nó de fundo, em essência, é o de que é impossível interpretar a condição humana sem levar em conta seus dois níveis constitutivos essenciais, os dois "níveis de organização" que a envolvem mais diretamente: o componente biológico e o componente histórico-social, que coexistem e se cruzam, mesmo que com diferentes pesos nas diferentes situações. Ocorre em qualquer rumo que uma pesquisa tome, de tal forma que resta impossível separá-los, atribuindo ao biológico o "individual", ao histórico-social o "coletivo". A "naturalidade" do indivíduo é irremediável e profundamente condicionada pelo nosso viver, desde o nascimento, na sociedade, a ponto de tal "naturalidade" não ser empiricamente verificável. De outro modo, cada sociedade humana é formada por indivíduos biologicamente constituídos, não podendo, por isto mesmo, não relacionar-se, mesmo que de formas historicamente heterogêneas, com suas necessidades e potencialidades "naturais".

Cada sociedade, portanto, não pode não responder - mesmo que de forma heterogênea e de maneiras desiguais - às exigências biológicas básicas da espécie humana. Tais respostas e, em certa medida, as próprias exigências, constituem-se como expressões específicas das específicas características de cada sistema social. Cada sociedade somente pode organizar-se a partir das características e das potencialidades somáticas e psíquicas inerentes à constituição biológica da espécie humana, tendo de selecionar e adestrar as potencialidades funcionais ao seu sistema de vida e aos papéis que o caracterizam. Assim, o social não se sobrepõe simplesmente ao biológico, constitui-se integrando os próprios indivíduos em uma rede de relações, como um sistema organizativo mais "complexo", a partir das naturalidades biológicas individuais, remodelando suas características.

Já foi dito em outro texto que atingimos recíproca autonomia e, ao mesmo tempo, relações de integração entre os dois níveis - biológico e social - aos quais coloca-se (e tem-se de indagar) a condição humana, cuja especificidade consiste justamente em colocar-nos, ao mesmo tempo, como produto de determinantes e correlações naturalístico-biológicas e como expressão da existência de uma organização social que nos transcende como indivíduos particulares e constitui-se como um sistema, condicionando-nos radicalmente, segundo uma lógica própria, relativamente autônoma, qualitativamente diferente, em relação àquela que regula os processos em que se manifesta nossa constituição biológica individual. Desta forma, em um mesmo indivíduo, quanto deriva do condicionamento social não é simplesmente sobreposição aos processos biológicos. A substituição de situações naturais por situações-estímulo qualitativamente novas - expressões históricas de arranjos de vida e de contextos ambientais socialmente produzidos - reestrutura profundamente todos os mecanismos biológicos de adaptação. A interposição de uma inevitável mediação social, às vezes muito complexa, no esquema de cada resposta comportamental às necessidades e às próprias pulsões instintivas, modifica em larga escala, suas formas e seu êxito naturais, adequando-os às condições de existência produzidas pelo sistema social, introduzindo inibições ou canalizações impostas pelos códigos culturais, agregando significados e funções novas, segundo esquemas sempre diferentes, em relação às diversidades das singulares situações históricas.

\section{A função e existência da cultura}

No decorrer do longo processo de hominização - cuja duração é estimada hoje em torno de quatro milhões de anos - os nossos antepassados organizaram-se, de fato e sempre mais fortemente, em redes de correlações coletivas (sistemas sociais), capazes de produzir, pelo impacto global do grupo e de uma articulação interna de funções, tipologias de resposta sempre mais calibradas e incisivas aos desafios ambientais. Nasceu, assim, um novo "nível de organização" da vida humana, o qual "funciona" como 
sistema, não como simples somatório dos indivíduos e das suas individuais capacidades. Desde as suas primeiras formas, esse novo "nível de organização" foi assumindo, justamente como sistema, uma relativa autonomia de funcionamento respeitante à lógica de funcionamento biológico dos próprios indivíduos que o integram e uma sempre mais rápida dinâmica de mudança histórico-social, em certa medida autônoma respeitante às mais lentas dinâmicas de mudança evolutivo-biológica. A transformação das civilizações, sua sucessão e sua diferenciação planetária produzem-se de tal modo: mediante processos internos à lógica dos sistemas sociais, no decorrer, portanto, de tempos históricos, durante os quais em termos biológico-evolutivos não se produz, de fato, sensível variação.

A constituição do sistema social, ou seja, de um nível de organização superior aos indivíduos particulares, teve influência decisiva no destino humano e levou o homem a atingir peso sempre maior no seu contexto ambiental e uma sempre progressiva autonomia em relação à "natureza externa". Produziu um complexo e estratificado sistema de relações entre indivíduos e um consequentemente recíproco, mesmo que desigual, poder de condicionamento. Determinou a formação de um novo constructo, a cultura, um patrimônio intersubjetivo de modelos mentais - representações cognitivas, valores, esquemas comportamentais - produzido aos poucos pelos indivíduos em função dos estímulos e dos problemas oriundos das concretas condições de existência das suas comunidades: em cada uma das quais, tais modelos resultam substancialmente compartilhados não somente por causa de uma relativa homogeneidade das situações e dos horizontes de referência, mas também, em larga escala, como consequência do desenvolvimento de uma rede estável de intercâmbios comunicacionais. Assim, por meio da produção social de símbolos e códigos, de redes de comunicação interindividuais e, portanto, também transgeracionais, os modelos mentais (culturais) puderam ser trocados e acumulados, de tal forma que, desde os tempos mais remotos, as comunidades humanas conseguiram dispor de grandes e orgânicos patrimônios coletivos de instrumentos cognitivo-operacionais funcionais para enfrentarem, de forma conjunta, as tarefas relacionadas ao seu sistema de vida: patrimônios muito mais ricos e "validados" do que aqueles que qualquer indivíduo poderia ter isoladamente produzido ao longo de sua própria vida, embasando-se exclusivamente nas próprias experiências pessoais (não comunicando a outros, teria, em todo caso, desaparecido junto com ele).

Deste modo, para qualquer indivíduo, a aquisição do patrimônio cultural da própria comunidade traduz-se não somente em uma enorme ampliação de modelos mentais disponíveis, mas também em um grande "simplificador social". Diante das situações que a cada momento se apresentam, ele não necessita construir sozinho, do nada, com todos os riscos de possíveis erros, os modelos interpretativos e operativos necessários, já que, diante de algum evento/tarefa/mensagem, já possui chave de leitura, instrumento de avaliação, esquema adequado de esperas e de respostas ou, pelo menos, orientação de acesso/encontro. Adquiriu isto mediante sua socialização e o consequente processo de enculturação, uma rica plataforma de modelos já validados e socialmente compartilhados. O que lhe permite concentrar-se, de forma mais fácil, sobre os elementos "novos", que exigem, portanto, certa criatividade cultural-pessoal. A comprovação disto está evidenciada, por outro lado, pelas dificuldades objetivas e pelas vivências subjetivas de isolamento e inadequação de quem, como os migrantes, entra de improviso em um contexto cultural diferente, ou seja, em um contexto "outro" daquele que lhe é usual.

A função e a própria existência da cultura parecem, em larga escala, um dado específico da condição humana: a constituição das redes comunicativas e a consequente patrimonialização coletiva dos modelos mentais - a formação. A cultura ou, ainda, a "consciência social" representa provavelmente a virada decisiva, o verdadeiro "salto de qualidade" produzido pela organização social da espécie humana e pela sua lógica interna de funcionamento sistêmico.

Neste sentido, o caráter coletivo (social) das respostas humanas aos desafios ambientais condicionou fortemente a própria direção do processo evolutivo (biológico). Não por acaso, os homens, na atualidade, são individualmente muito mais fracos, do ponto de vista físico, que seus ancestrais, e são, por outro lado, dotados de um aparelho neuropsíquico muito mais complexo, funcionalmente conectado às complexidades dos processos de elaboração e troca cultural construído socialmente ao longo do tempo para enfrentarmos coletivamente nossa condição existencial.

Seria bom demorar um momento - mesmo sob forma esquemática - em alguns aspectos da cultura e alguns dos seus mecanismos de formação e transformação, que evidenciam sua determinante função 
intermediadora entre indivíduo e contexto, constante interação com o funcionamento globaldo sistema social:

a) O enraizamento das culturas em horizontes concretos naturais e histórico-sociais aparece tematicamente orientado e focalizado sobre as situações e tarefas que os indivíduos têm em função do território e da organização social em que estão inseridos. Estratégias de atenção, representações do mundo, saberes, valores, metas de vida, modelos, papéis e técnicas de trabalho - qualidades humanas privilegiadas, inteiro perfil cultural - relacionam-se funcionalmente, em cada comunidade, com os problemas criados pelas concretas condições dentro das quais os homens embasam sua existência, seus mecanismos de sobrevivência, diferentes, por certo, numa comunidade de pescadores, vilarejo campesino, tribo de pastores nômades ou entre cidadãos de uma metrópole industrial.

b) As sociedades estruturalmente estratificadas, articuladas em segmentos sociais caracterizados por funções heterogêneas e condições de vida (consequentemente, por assimétricas relações de poder), manifestam certo grau de heterogeneidade cultural interna. Pontos de vista, modelos, papéis e competências dos indivíduos colocados em diferentes posições na estrutura geral do sistema, mesmo compartilhando algumas orientações de fundo, manifestam - inevitavelmente - diferenças subculturais sensíveis. Podemos afirmar que os patrimônios culturais dos indivíduos resultam tanto mais heterogêneos quanto mais heterogêneas são as condições e experiências - diretas ou "comunicacionais" - dos seus percursos biográficos e vice-versa.

c) Nas sociedades estratificadas os diversos segmentos sociais têm um peso diferente nos mecanismos de produção e circulação cultural. Frente às situações concretas, cada segmento expressa uma possibilidade peculiar de resposta interpretativa e operativa e uma capacidade peculiar de elaborar autonomamente modelos culturais e difundi-los no espaço social. Cada segmento, contudo, expressa uma diferente abertura à aceitação de modelos formulados e difundidos por outros segmentos sociais. $\mathrm{A}$ esta capacidade de alguns segmentos do sistema social de produzir em constructos mentais e de influenciar, mediante processos específicos, o patrimônio cultural de outros segmentos, definimos como hegemonia. Por meio deste processo, os grupos que direcionam os mecanismos de funcionamento de um sistema social e estabelecem suas regras - colocando-se, portanto, em uma situação de poder são, geralmente, capazes de condicionar de maneira determinante também os modelos mentais e os estilos comportamentais das outras camadas sociais, orientando-as para práticas funcionais à reprodução da ordem social existente (a ordem social dentro da qual tais grupos determinam sua posição dominante). $O$ patrimônio cultural das camadas subalternas resulta fortemente determinado "pelo alto", embasado no papel que elas têm de atuar na "perfeita" reprodução do sistema social dentro do qual devem continuar sendo subalternas. Isso acontece mediante um jogo complexo de processos de controle social, não somente fundados sobre mecanismos de coerção/repressão, mas atuados, em larga escala, em uma rede articulada de organizações e intermediações formadoras das orientações culturais e dos modelos de comportamento, embasado em estratégias institucionais específicas e como consequência da própria experiência diária de cada indivíduo dentro da lógica de funcionamento do seu próprio contexto e de sua aparente "obviedade". Ficamos diante de um nó metodológico central para a interpretação da subjetividade e dos comportamentos individuais e dos grupos - que não podem ser compreendidos se não dentro deste quadro sistêmico - e também para a própria interpretação global do funcionamento dos sistemas sociais "estratificados" nos quais, frente a grandes maiorias subalternas, a gestão do poder e de suas regras e a maior disponibilidade de bens socialmente produzidos concentram-se em minorias limitadas e privilegiadas. Nenhuma forma de poder, em uma sociedade "estratificada" - caracterizada, portanto, por uma real e significativa iniquidade de bens e direitos - poderia de fato sustentar-se mediante processos de controle social exclusiva ou preferencialmente fundados sobre mecanismos de pura e simples coerção/repressão. Os grupos que estão no topo da sociedade exercitam seu poder e sua capacidade de direção por meio de processos de conformação cultural de todos os estratos sociais às regras do sistema e ao papel a eles designados para seu funcionamento global. Mediante este "condicionamento preventivo à conformidade", essas regras aparecem como "óbvias" e os comportamentos desviantes resultam extremamente reduzidos, de tal forma que, no quadro dos processos de controle social, sua repressão mais ou menos intensa e mais ou menos ampla dependendo dos regimes políticos - resulta sempre, respeito aos processos de hegemonia, como a 
menor cota, a "exceção", a "última instância", que ocorre nos casos limitados em que a hegemonia não teve sucesso. Com importantes implicações: a tomada de consciência relativa ao significado dos processos de hegemonia e a sua importância na determinação das propensões, das opiniões e das próprias opções políticas, comporta inevitavelmente - sobretudo em uma sociedade "midiática" como a nossa, caracterizada por poderes comunicativos largamente assimétricos - a necessidade e a oportunidade de se rediscutir o conceito de liberdade como mera ausência de coerção e, ao mesmo tempo, de definir de maneira não ingênua e não simplista as regras de uma democracia real.

d) Nas sociedades "estratificadas", a heterogeneidade das condições de existência e experiência dos vários segmentos sociais e os efeitos heterogêneos que determinam, nos diferentes segmentos, os processos de hegemonia e circulação cultural, produzem inevitavelmente uma segmentação da própria cultura ou, em outras palavras, uma diferente configuração nos vários extratos em que a sociedade está organizada. Ainda assim, mesmo caracterizada por certo grau de heterogeneidade interna, a cultura pode permanecer globalmente coerente na medida em que os patrimônios culturais das diferentes camadas se colocam todos dentro de uma única lógica sistêmica: a lógica de funcionamento da formação econômico-social existente. Nas sociedades feudais, por exemplo, o funcionamento global do sistema e de suas formas de poder era garantido pela produção de uma heterogeneidade cultural coerente entre os diversos atores sociais que as constituíam (senhores feudais, servos da gleba, artesãos), uma diversidade que se traduzia no desempenho das diferentes funções atribuídas pela lógica do sistema a cada um desses atores. Portanto, uma cultura internamente heterogênea resulta, em função desta diversidade, globalmente coerente.

e) A existência de uma heterogeneidade de modelos e patrimônios culturais, dentro de uma sociedade, até mesmo dentro de um segmento, pode expressar uma real incoerência do conjunto de sua cultura, no sentido da coexistência de modelos mentais funcionais à lógica do sistema social existente e de outros que se colocam fora dessa lógica e resultam, portanto, incongruentes e, de qualquer forma, alternativos. Tal condição, presente nas sociedades caracterizadas por certo grau de dinamismo, marca largamente todas as épocas históricas, como a nossa, em que se manifestam processos de rápida mudança e/ou de interação significativa entre diferentes contextos de civilização. Estes elementos de incoerência cultural - difusamente distribuídos no tecido social - aparecem, normalmente, em derivação de duas grandes ordens de dinâmicas conjunturais. Primeiro, a presença, junto com a cultura expressa pelo regime social dominante, de expressões culturais que remetem a aspectos de um regime anterior, já superado ou marginalizado pelos mecanismos sociais dominantes ou, ao contrário, a expressões culturais onde se manifesta a antecipação de novas lógicas sociais ainda não afirmadas integralmente, de qualquer forma, expressões de uma rápida transição de sistemas sociais. Nesses casos, nos deparamos com resistência conservadora ou, ao contrário, com capacidade relativamente autônoma de produção e difusão cultural. Portanto, de uma possível (mesmo que parcial) nova hegemonia por parte de grupos sociais antagônicos em relação àqueles dominantes: últimas manifestações de regimes ultrapassados ou, ao contrário, vanguardas empenhadas em uma estratégia de mudança do regime dominante. Segundo, o ingresso de elementos culturais provenientes do exterior, de outros sistemas sociais, isto é, fenômenos de aculturação e efeitos de interação nos territórios "de fronteira", por exemplo, ou fenômenos de "influência a distância" (importação de objetos ou de técnicas produzidas em outros lugares ou influências midiáticas) ou ainda consequências da chegada de "outra" (diferente) cultura (imigrantes, escravos importados com o tráfico, colonizadores), com diferentes resultados, evidentemente, em relação à sua consistência numérica e, sobretudo, nas suas relações de poder com a população nativa. Em toda esta casuística, vemos produzir-se, dentro de uma sociedade, a presença de elementos culturais incoerentes com a lógica do regime dominante que podem gradualmente desaparecer ou, ao invés disso, afirmar-se definitivamente ou reagir ao "novo", persistindo, de certo modo, mediante processos de refuncionalização ou, ainda, integrar-se com os modelos locais (sincretismo, crioulização).

Substancialmente, consolidam-se, nas sociedades (e em suas diferentes camadas), os modelos culturais que - nas condições dadas e nas relações efetivas de hegemonia e de poder - consentem mais realisticamente que os indivíduos possam interagir entre eles e enfrentar de forma mais eficaz as tarefas que têm a cumprir: modelos que, ao encontrarem uma verificação diária concreta de funcionalidade 
operacional no sucesso dos comportamentos que eles produzem em situações reais, podem persistir mesmo por muito tempo, ao longo de gerações, ou deixar lugar ao aparecimento de novos modelos, na medida em que a ação dos homens e da natureza, ou um deslocamento territorial de uma comunidade, traduzem-se em mudança de contextos de referência, causando, deste modo, a disfuncionalidade dos modelos anteriores, sua obsolescência e um inevitável processo ativo de remodelagem e mudança cultural.

Não se faz a história das culturas e nem, portanto, sua interpretação, se não em relação à história concreta dos homens que as produzem e as utilizam dentro de contextos histórico-sociais determinados: dos homens, portanto, e dos sistemas sociais dentro dos quais eles ativamente se situam, em posições determinadas, dentro de específicas redes de relações, frente a situações e possíveis respostas também historicamente determinadas. É neste quadro sistêmico que toma forma o mecanismo de suporte do processo histórico, a perene dialética histórico-social entre as condições materiais da existência dos homens colocados em contextos sociais historicamente determinados e as formas históricas de sua consciência e, portanto, a produção e a transformação das culturas.

\section{Compartilhamento emocional interindividual e modelos individualistas de competição}

A hipótese de que, dentro do forte condicionamento que os indivíduos sofrem por parte de contextos particulares de uma ou outra civilização, operem também fatores "mais permanentes", inerentes a qualquer contexto de vida social, parece hoje bastante plausível, mesmo que seja provável que nos diferentes contextos tais fatores possam ter resultados heterogêneos. Fundamentalmente, falamos da existência e da importância de elementos presentes em todas as civilizações, ou seja, comuns a "todos os homens", sem que eles derivem da substancial homogeneidade da atual constituição biológica da espécie humana: a hipótese, em outras palavras, de um "universalmente humano" de caráter meta-histórico, mas de matriz social. Não me refiro à questão, muitas vezes colocada, da universalidade do tabu do incesto. Parece-me mais interessante sublinhar uma condição de fundo comum a todos os homens: que para satisfazer suas necessidades, mesmo as mais elementares, todo indivíduo - em qualquer tipo de sociedade - tem de se deparar com sua inevitável dependência de uma "negociação" e de uma "ativa intermediação" com outros homens, vivendo, por isso,

constantemente, na necessidade objetiva, mas também subjetiva, de uma relação positiva, mesmo que mínima, com seu contexto relacional. O que parece ter muitas implicações na estruturação dos equilíbrios psíquicos pessoais.

Esta condição geral parece articular-se em uma miríade de situações conectadas com o contexto de sociedades específicas e com a posição e história pessoal dos indivíduos que as constituem. Dessa forma, as regras de funcionamento dos diferentes sistemas sociais traduzem-se numa maior ou menor "abertura" à necessidade - comum aos homens de qualquer sociedade - de viverem dentro de redes positivas de relações sociais no seu entorno. Assim, por exemplo, na constituição de uma perturbação psíquica hoje muito frequente - o sempre mais difuso sentimento de solidão depressiva que atinge grande parte das camadas sociais na nossa civilização - pesa fortemente a contradição que se origina da própria lógica do nosso sistema social, entre a necessidade operacional e emocional que impulsiona todo indivíduo em direção à cooperação, solidariedade e compartilhamento emocional interindividual e, de outro lado, os modelos individualistas de competição exasperada que operam em cada uma das esferas da vida social junto com a desagregação dos laços de suporte primário.

Claramente, com relação aos fenômenos cada vez examinados, os determinantes biológicos e histórico-sociais manifestam, nos vários casos, uma importância heterogênea, um peso específico, por vezes, bem diferente. Em alguns casos, um ou outro desses determinantes parece quase irrelevante, o que se reflete na própria instrumentação conceitual das diferentes disciplinas que constituem, no seu conjunto, as ciências humanas. Na disciplina de Anatomia Humana, para exemplificar, normalmente resta excluída, em uma aproximação inicial, toda referência à história econômico-social, mesmo que saibamos que o comprimento do fêmur e nossa própria altura aumentaram sensivelmente no último século por causa da importante melhoria das condições alimentares e de vida e, portanto, das suas 
consequências sobre nosso fenótipo. Por outro lado, nos estudos de História da Arte podemos, em uma aproximação inicial, excluir (ou melhor, considerar como óbvia) a consideração de que a forma da mão humana e a neurofisiologia do nosso sistema visual e da nossa percepção cromática das ondas luminosas constituem uma pré-condição necessária do trabalho e dos resultados produtivos de um pintor. Trata-se justamente, nesses casos, de pré-condições relativamente estáveis ou que, pelo menos em uma aproximação inicial, podem ser consideradas como "pano de fundo".

A interação entre o "biológico" e o "social", contudo, está no próprio centro da indagação: no estudo destas áreas, as distintas ciências humanas, cujo referencial é, em geral, um só dos dois níveis de organização da humanidade - "biológico" ou "social" - têm de, necessariamente, convergir na direção de uma integração mais imediata, pois, na ausência desta, toda interpretação aparece fragmentada e carente.

Com essas características, evidenciam-se pelo menos quatro grandes áreas de integração mais próxima:

a) da alimentação como resposta social a uma necessidade biológica primária, a necessidade da nutrição: uma resposta social enraizada nos modos de produção e nas técnicas de trabalho, com importantes implicações simbólicas e emocionais, numerosas funções secundárias e consequências psíquicas e psicossomáticas precoces;

b) da sexualidade: nenhuma pulsão biologicamente determinada, provavelmente, sofreu, na história da humanidade, no campo das relações sociais, um tão heterogêneo e tão rígido arco de interdições, canalizações, implicações simbólicas e emocionais, sanções ético-morais e normativas, projeções organizativas e institucionais, de tal forma que é difícil, agora, distinguir suas diferentes raízes;

c) das técnicas corpóreas: resultado da seleção e do adestramento sociocultural das potencialidades biológicas do corpo humano coerentes com as tarefas e os estilos comportamentais previstos nos contextos sociais específicos; e

d) do processo saúde/doença: área na qual a medicina moderna aprofundou-se com sucesso crescente, focalizando progressivamente sua complexa dimensão biológica (disease); com relação à qual, todavia, aparece sempre mais claro - como antecipado, sobretudo pelas disciplinas psi e pela pesquisa antropológica - o peso das condições e dos estilos de vida, das dinâmicas socioculturais e relacionais e das vivências subjetivas (illness); e o peso das "regras" que definem, nas diferentes sociedades, o estatuto social de quem adoece (sickness), de tal forma que a recomposição dos saberes, até agora adquiridos por diferentes vias disciplinares, parece hoje uma necessidade primária.

\section{Determinantes sociais e dinâmicas psíquicas}

Podemos retomar, ainda que brevemente, à temática dos determinantes sociais das patologias humanas e focalizar, em particular, um de seus "percursos" : a função moduladora que, em relação às defesas orgânicas, é atuada pelas dinâmicas psíquicas, isto é, a dimensão da subjetividade como lugar da ativa intermediação, em cada indivíduo, entre a esfera relacional e a biológica. Sobre esta questão versa um difícil debate interdisciplinar iniciado há mais de um século e que, somente agora, insinua-se resolver.

Voltemos à segunda metade do século XIX, ao clima de crescente laicismo cultural marcado pelo positivismo e pelas descobertas revolucionárias feitas naqueles anos no âmbito das ciências naturais: evolução das espécies, processo de hominização, existência dos microrganismos e etiologia microbiana de muitas doenças infecciosas. Naqueles anos, de fato, a medicina ocidental passou a concentrar uma atenção quase exclusiva às dimensões biológicas das patologias. Anunciava-se um horizonte de grandes sucessos cognitivos e operacionais. A biologia parecia, então, por muitos motivos, como o terreno científico de vanguarda, aquele que visivelmente "premiava", o que representava a verdadeira prova do rigor e da "objetividade" de um trabalho de pesquisa sério. Naqueles anos a medicina ocidental abandonou, com pouquíssimas exceções, um real interesse pelo quadro relacional dos pacientes e suas experiências de vida, que havia, ao invés disso, caracterizado a investigação e o debate sobre as causas dos fenômenos patológicos desde o século XVII: exclusão da subjetividade e do social, que pesa fortemente até hoje. No próprio interior do campo biológico, um aprofundamento sempre mais rigoroso 
e positivo dos vários "objetos" correspondeu a uma progressiva setorialização dos saberes e consequente ulterior corrosão de uma visão sistêmica global.

A atenção à subjetividade nas dinâmicas dos processos saúde/doença e seus fatores relacionais e socioculturais desenvolveu-se, desta forma, por um período bastante longo, fora do campo médicoinstitucional, seguindo linhas de investigação do âmbito das disciplinas psi e antropológicas.

Não é este o momento de reconstruir em detalhes esse complexo, articulado e por vezes tortuoso percurso, em direção ao qual somente há pouco tempo parece estar finalmente iniciando convergir também a biomedicina. Valeria a pena, porém, recordar com simples notas, alguns pontos nodais deste progressivo reconhecimento, que abrange pouco mais de um século e que pode ser sintetizado com fórmula um pouco esquemática: "a psique pode fazer adoecer, a psique pode curar".

Em 1890, Freud dedica páginas significativas à observação de que, nos mecanismos de cura, a relação do paciente com o terapeuta e a confiança nas suas capacidades desenrolam uma função tão importante quanto aquela constituída pelo medicamento prescrito pelo médico (Freud, 1967). Em 1892, o grande psiquiatra da clínica Salpêtrière, Charcot, intervém no incandescente debate sobre casos de faith-healing aberto pelas "milagrosas curas" de Lourdes, superando, por um lado, as posições daqueles que atribuíam esses casos ao aparecimento sobrenatural da Virgem Maria e, por outro, as que, ao contrário, negavam simplesmente a autenticidade da cura. Num texto, rapidamente famoso, ele afirma que curas desse tipo podem certamente ocorrer, mas sua causa deve ser atribuída à produção de estados psíquicos particulares nos próprios doentes, uma fé absoluta na cura, um intenso estado subjetivo de espera, reforçado, por outro lado, pelo pathos coletivo da peregrinação. Em 1913, um renomado antropólogo francês, Saintyves, concluindo uma cuidadosa investigação sobre o sucesso dos curandeiros que, no interior da França, curavam as verrugas por meio de rituais "mágicos" - sucesso amplamente documentado mesmo recentemente na Itália e em outros países - propõe interpretação igualmente centrada na função de um psiquismo ativado pela certeza da eficácia de tais práticas, por parte dos pacientes, plausível no contexto da cultura tradicional camponesa. Em 1926, Mauss, uma figura central na socioantropologia francesa do século $X X$, apresenta ampla documentação, de origem australiana e polinesiana, sobre mecanismo análogo, mas de sentido oposto, sobre os efeitos mortais produzidos pela certeza de "dever morrer" (por causa da violação de um tabu, por exemplo): uma certeza culturalmente induzida pelo contexto social (Mauss, 1966). É uma temática que será outras vezes retomada na pesquisa antropológica, como no decorrer do longo debate realizado de 1942 até quase final dos anos 1980 na América do Norte, sobretudo nas revistas "American Anthropologist" e "Psychosomatic Medicine", ao redor da interpretação da "morte por vodu", e depois em importante ensaio de Lewis na Grã-Bretanha em 1977. Já em 1949, a atenção dos estudiosos foi atraída pelo ensaio de Lévi-Strauss, analisando o longo texto de um canto produzido por um xamã cuña (uma população indígena da América Central) para ajudar em um parto doloroso e difícil: ensaio rapidamente famoso, onde o bom êxito da intervenção xamânica foi interpretado segundo a hipótese de que o canto constitui, nessas situações, "uma manipulação psicológica do órgão doente", e é utilizada, para este propósito, a expressão amplamente difundida, apesar de certa ambiguidade semântica, de eficácia simbólica.

Desde 1923, a importância do psiquismo nos processos saúde/doença e naqueles de cura tinha sido organicamente enfrentada num texto de um grande psicopatologista francês daquele tempo, Janet; e a corrente psicanalítica havia largamente explorado - em termos teórico-práticos - os processos definidos por somatização: uma linha de integração entre psicanálise e medicina, da qual também nasceria mais tarde a reflexão que, iniciando com Viktor von Weizsäcker, até Arminda Aberastury e Victor Chiozza, da Alemanha à Argentina, produziu, no terreno teórico, empírico e operacional, o instrumento da "patografia" e, de forma mais geral, a ideia de forte relação entre orientações da personalidade e prováveis direções da patologia individual, a assim chamada psicossomática psicanalítica.

Sobre esta problemática, a reflexão interna à biomedicina, com poucas exceções amadureceu muito mais tarde. Importantes observações vieram, é verdade, da neurofisiologia soviética, já em 1935, graças a um aluno de Pavlov, Speranskij, a propósito da influência do sistema nervoso central na patogenia de algumas doenças infecciosas de clara origem bacteriana. Além do desenvolvimento progressivo e bastante autônomo das várias correntes da medicina psicossomática - que sempre conservaram uma 
relação com a matriz psicanalítica. Só há pouco tempo a medicina ocidental passou a manifestar interesse efetivo e concreto pela influência do psiquismo nos processos saúde/doença, o que é bastante paradoxal se considerarmos que, mesmo que só para uma utilização ligada à avaliação da eficácia específica dos novos fármacos, a biomedicina já maneja há muito tempo conceitos como o de efeito placebo e efeito nocebo.

Este mais recente interesse, na biomedicina, foi desenvolvido ao longo de três linhas de investigação. Uma primeira trabalhou centralmente sobre o peso dos estados emocionais na produção e no desenvolvimento das doenças chamadas orgânicas, cruzando-se, assim, com as muitas pesquisas da antropologia médica sobre a crença - atestada em numerosas culturas folclóricas, sobretudo na América Latina - de que um susto forte e imprevisto possa constituir a causa de graves distúrbios, também, em dimensões que chamaríamos hoje somáticas. Uma segunda, mais recente, que podemos, um pouco apressadamente, denominar por estatístico-epidemiológica, chegou a estabelecer a existência de correlações significativas entre estados psíquicos - de tipo depressivo, por exemplo - e a vulnerabilidade a determinadas patologias infecciosas (em geral, "somáticas") retomando, assim, neste terreno, aquilo que tinha sido colocado em evidência, muitos anos antes, como por Speranskij. Uma terceira, que de qualquer modo parece decisiva - porque não se limita a acertar as correlações entre psiquismo e saúde/ doença, mas busca descobrir seus mecanismos - é representada por uma nova disciplina que vem sendo desenvolvida no Ocidente nos últimos cinquenta anos: a psiconeuroendocrinoimunologia, ou seja, o estudo dos mecanismos complexos e dos vários canais por meio dos quais o sistema nervoso central consegue modular o nosso sistema imunitário.

Em certo sentido, o desenvolvimento da psiconeuroendocrinoimunologia permite, pela primeira vez, verificar uma medicina científica capaz de incorporar e integrar as contribuições da biomedicina com a importante função da intermediação psíquica entre os estímulos relacionais e os processos corpóreos, produzidos pela psicologia, pela antropologia e pelas ciências sociais em geral. Recupera, em uma perspectiva epistemologicamente unitária, tantas "verdades" propostas pelas muitas medicinas folclóricas e não ocidentais, permitindo iniciar a edificação de uma medicina científica ao menos integrada ou, finalmente, sistêmica.

\section{Considerações finais}

Durante a segunda metade do século XIX teve início o quase ininterrupto percurso de vitoriosas conquistas da medicina científica moderna e constituíram-se, também de forma institucional, não somente a antropologia, mas outras ciências humanas fundamentais, como a psicologia e a sociologia. Foi um período fortemente caracterizado pelas ideias do positivismo, extremamente fecundo, mas marcado por um forte, ainda que desigual, reducionismo biologicista.

Durante este percurso complexo e contraditório, entrelaçado com a contemporânea construção ideológica e institucional de novas estruturas de Estado e de novos impérios coloniais - o ofuscamento dos fatores sociais da condição humana levou a enormes erros interpretativos e a uma infundada legitimação de uma grave hierarquização entre os dois sexos e entre os diversos grupos étnico-culturais e, consequentemente, a pesados processos de exclusão, opressão e repressão das populações extraeuropeias, das classes subalternas, da loucura e de todas as formas de desvio, e até da própria "metade feminina" das sociedades europeias que julgavam ter alcançado o vértice da evolução humana. Durante anos, em nome dos efeitos positivos de uma "seleção dos mais aptos", que se supunha produzida, se livres de interferências sociais, pelos mecanismos evolutivos "naturais", foi possível negar, em numerosos fóruns, a oportunidade de qualquer investimento público destinado ao sustento e à saúde das classes pobres (a teoria do assim chamado "darwinismo social").

Como é sabido, a superação do positivismo seguiu, nos vários países, caminhos nem sempre iguais, produzindo, de qualquer modo, em maior ou menor medida, uma fratura dos saberes e das sensibilidades intelectuais, que foi chamada de "duas culturas": "científica" e "humanística", separadas entre si.

Na Itália, onde, em oposição ao positivismo, afirmou-se no setor das "humanidades" desde o princípio do século XX e, depois, durante o fascismo, um historicismo idealístico tingido, por vezes, de 
elementos retomados dos vários espiritualismos contemporâneos, o fenômeno das "duas culturas" e da separação dos seus currículos formadores, pesou mais gravemente e por mais tempo que em outros lugares. Levou à total separação entre uma "antropologia física", estritamente naturalística, e uma atenção idealística ao social, unicamente dirigida aos percursos históricos, e ao grave enfraquecimento global das ciências humanas mediante a quase total eliminação, até a metade do século, daquelas como a antropologia sociocultural, a psicologia e a sociologia - que teriam permitido garantir, realmente, uma ponte entre as duas áreas.

Em outros lugares, sobretudo na França e nos países anglo-saxônicos, onde teve lugar um incremento paralelo mais equilibrado da pesquisa naturalística e daquela socioantropológica e psicológica, o problema da relação entre os dois grandes compartimentos das ciências humanas continuou, de diferentes maneiras, a ser proposto, e foram iniciadas significativas, ainda que parciais, tentativas de intersecção e integração. Comprovam-no, por exemplo: as recorrentes propostas de uma teoria das assim chamadas "necessidades humanas", pesquisas sobre a relação entre repressão sexual e personalidade, "revisões sociais" da psicanálise freudiana clássica, interpretações do agir humano formuladas pelos etólogos e sociobiólogos e, em geral, o forte confronto ao redor da importância da herança genética e dos fatores sociais no desenvolvimento das potencialidades corpóreas e na constituição das propensões individuais e dos estilos comportamentais. Trata-se, todavia, de tentativas que permaneceram setoriais, viciadas pela parcialidade das abordagens e pelas consequentes aporias, restritas num estéril contraste entre o risco "biologicista" e o risco "sociologicista".

A questão de fundo, para iniciarmos a construir um sistema orgânico das ciências humanas e para edificarmos, desta forma, uma antropologia geral, creio, portanto, seja aquela cujo perfil tentei esboçar: a de que um efetivo delineamento científico dos estudos sobre o homem somente se funda em uma abordagem sistêmica, embasada nos dois níveis em que se organiza a condição humana e se realiza a sua relação com o contexto ambiental (nível biológico e nível histórico-social); que esses níveis sejam examinados e interpretados, tendo em conta suas relações de integração e ao mesmo tempo sua recíproca autonomia e especificidade. Somente nesta perspectiva poderia ter sentido e valor heurístico uma articulação dos estudos sobre o homem em ciências humanas específicas, com uma autonomia, ainda que relativa e ao mesmo tempo com uma possível convergência interpretativa e operacional. Apenas embasando-se nesta abordagem seria possível harmonizar os três modelos interpretativos que, separados, caracterizaram, até nas denominações verbais, as três principais "correntes" da antropologia moderna, privilegiando, respectivamente, a abordagem da estrutura ou da função ou, ainda, da historicidade.

Nesta perspectiva, sem dúvida, muito ainda precisa ser trabalhado sobre o terreno das aquisições empíricas necessárias e sobre aquele das construções interpretativas, mas parece-me muito importante, no trabalho em saúde, manter constantemente aberto um horizonte de referência sistêmico e unitário. 
Bibliografia

BOTTACCIOLI, F. Psiconeuroendocrinoimmunologia: i fondamenti scientifici delle relazioni mente-corpo: le basi razionali della medicina integrata. 2.ed. Milão: Red Edizioni, 2005.

CANNON, W.B. Voodoo death. Am. Anthropol., v.44, n.2, p.169-81, 1942.

CHARCOT, J.-M. Les démoniaques dans l'art suivi de la foi qui guérit. Paris: Macula, 1984.

CHIOZZA, L. Per un incontro tra medicina e psicoanalisi, a cura di Carlo Brutti e Rita

Parlani. In: (Nuova serie, 31). Quaderni di Psicoterapia Infantile. Roma: Edizioni Borla, 1995.

FREUD, S. Trattamento psichico (Trattamento dell'anima). In: Opere, 18861895. Turim: Boringhieri, 1967. v.1.

GALLINI, C. Il miracolo e la sua prova: una etnologa a Lourdes. Nápoli: Liguori Editore, 1998.

GRUPPI, L. Il concetto di egemonia in Gramsci. Roma: Editori Riuniti, Istituto Gramsci, 1972.

GUIZZARDI, G. Miracoli e portenti: un modo diverso di guarire. In: (Org.)

Star bene, benessere, salute, salvezza tra scienza, esperienza e rappresentazioni pubblique. Bolonha: II Mulino, 2004. p.121-68.

HROBJARTSSON, A.; GOTZSQUE, P.C. Is the placebo powerless? An analysis of clinical trials comparing placebo with no treatment. New Engl. J. Med., v.344, n.21, p.1594-602, 2001.

JANET, P. La medicina psicologica. Roma: Il Pensiero Scientifico Editore, 1994.

LÉVI-STRAUSS, C. L'efficacia simbolica. In: Antropologia strutturale. Milão: II Saggiatore, 1966. p.210-30.

LEWIS, G. La paura della stregoneria e il problema della morte per suggestione. AM - Riv. Soc. Ital. Antropol. Med., n.3-4, p.281-312, 1987.

MAUSS, M. Teoria generale della magia e altri saggi. Turim: Einaudi, 1966.

RUBEL, A.J.; O'NELL, C.W.; COLLADO-ARDÓN, R. Susto, a folk illness. Berkeley: University of California Press, 1984.

SAINTYVES, P. La guérison des verrues: de la magie médicale à la psychothérapie. Paris: Librairie Critique Émile Nourry, 1913.

SEPPILLI, T. Per una antropologia della alimentazione: determinazioni, funzioni e significati psico-culturali della risposta social ad un bisogno biologico. La ricerca folklorica: contributi allo studio della cultura delle classi popolari, n.30, p.7-14, 1994.

Una interpretazione sistemica della condizione umana. In: MINELLI, M.; PAPA, C. (Orgs.). Scritti di antropologia culturale. Firenze: Leo S. Olschki Editore, 2008. tomo I, p.127-50.

SPERANSKIJ, A.D. La partecipazione del sistema nervoso nella patogenesi di certe malattie infettive. In: 1956. p.161-205. . Fondamenti per una teoria della medicina. Turim: Einaudi,

VADALÀ-PAPALE, G. Gli ospedali e il darwinismo: studi sociologici. Roma: Forzani, C. Tipografia del Senato, 1884. 
A interpretação do processo saúde/doença tem sido marcada pelo positivismo e pelas ciências naturais. A medicina/saúde ocidental concentrou uma atenção quase exclusiva às dimensões biológicas das patologias, demarcando sucessos cognitivos e operacionais, a biologia representando a verdadeira prova de rigor e objetividade. A função moduladora em relação às defesas orgânicas era atuada pelas dinâmicas psíquicas, a dimensão da subjetividade como lugar da ativa intermediação, em cada indivíduo, entre as esferas relacional e biológica. O reconhecimento dos fatores comportamentais e socioculturais desenvolveu-se fora do campo médico-institucional, seguindo linhas de investigação das disciplinas psicológicas e antropológicas. O texto tenta esboçar que um efetivo delineamento científico dos estudos sobre o homem somente pode fundar-se em uma abordagem sistêmica, em que os níveis biológico e histórico-social, que organizam a condição humana e realizam sua relação com o contexto, precisam ser examinados e interpretados em suas relações de integração, em sua recíproca autonomia e especificidade.

Palavras-chave: Antropologia médica. Ciências humanas. Cultura e saúde. Formação em saúde. Educação e cultura da saúde.

Health and anthropology: contributions to the interpretation of the human condition in the health sciences

The interpretation of the health/disease process has been marked by positivism and by the natural sciences. Western medicine/health has focused almost exclusively on the biological dimensions of pathologies, delimiting cognitive and operational successes, biology representing the true proof of rigor and objectivity. The modulating function in relation to the organic defenses used to be enacted by the psychic dimensions, the dimension of subjectivity being the place of the active intermediation, in each individual, between the relational and biological spheres. The recognition of the behavioral and sociocultural factors was developed outside the medical-institutional field, following lines of investigation of the psychological and anthropological disciplines. The text tries to outline that an effective scientific design of the studies about man can only be founded on a systemic approach, in which the biological and historical-social levels, which organize the human condition and realize its relation to the context, need to be examined and interpreted in their relations of integration, in their reciprocal autonomy and specificity.

Keywords: Medical anthropology. Human sciences. Culture and health. Health education. Education and health culture.

Salud y antropología: contribuciones a la interpretación de la condición humana en ciencias de la salud

La interpretación del proceso salud/enfermedad ha sido marcada por el positivismo y por las ciencias naturales. La medicina/salud occidental concentró atención casi exclusiva a las dimensiones biológicas de las patologías, demarcando sucesos cognitivos y operacionales, representando la biología una verdadera prueba de rigor y objetividad. La función moduladora en relación a las defensas orgánicas era actuada por las dinámicas psíquicas, la dimensión de la subjetividad como lugar de activa intermediación en cada individuo, entre las esferas relacional y biológica. El reconocimiento de los factores comportamentales y socio-culturales se ha desarrollado fuera del campo médico-institucional, siguiendo líneas de investigación de las disciplinas psicológicas y antropológicas. El texto intenta esbozar que un efectivo delineamiento científico de los estudios sobre el hombre sólo se puede apoyar en un enfoque sistémico en que los niveles biológicos e histórico-sociales que organizan la condición humana y realizan su relación con el contexto necesitan examinarse e interpretarse en sus relaciones de integración, en su recíproca autonomía y especificidad.

Palabras-clave: Antropología médica. Ciencias humanas. Cultura y salud. Formación en salud. Educación y cultura de la salud. 